\title{
Correction to: Evaluation of the Variations in the Levels of Perioperative Inflammatory Markers After Open Reduction and Internal Fixation of Maxillofacial Fractures
}

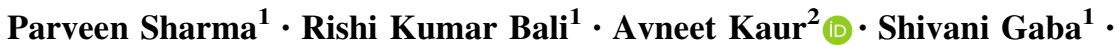 \\ Guneet Dhillon ${ }^{3}$
}

Published online: 8 June 2020

(C) The Association of Oral and Maxillofacial Surgeons of India 2020

\section{Correction to: J. Maxillofac. Oral Surg.} https://doi.org/10.1007/s12663-018-1174-4

The article Evaluation of the Variations in the Levels of Perioperative Inflammatory Markers After Open Reduction and Internal Fixation of Maxillofacial Fractures, written by Parveen Sharma, Rishi Kumar Bali, Avneet Kaur, Shivani Gaba and Guneet Dhillon, was originally published

electronically on the publisher's Internet portal (currently SpringerLink) on 20 November 2018 with open access. With the author(s)' decision to step back from Open Choice, the copyright of the article changed on 10 May 2020 to CThe Association of Oral and Maxillofacial Surgeons of India 2020, and the article is forthwith distributed under the terms of copyright. The original article has been corrected.

The original article can be found online at https:// doi.org/10.1007/s12663-018-1174-4.

Avneet Kaur

avneetsoni7@gmail.com

Parveen Sharma

parveen66@yahoo.co.in

Shivani Gaba

dr.shivanigaba@gmail.com

1 Department of OMFS, DAV(C) Dental College and Hospital,

Yamunanagar, Haryana, India

2 Department of OMFS, Indira Gandhi Government Dental College and Hospital, Jammu, India

3 Department of OMFS, Rayat Bahra Dental College and Hospital, Chandigarh, India 